\title{
PAKIEM Era Hybrid Learning
}

$D_{10}$

i era saat ini, pembelajaran tidak hanya sebatas lintas fisik saja, tetapi sudah merambah pada pemanfaatan teknologi sebagai penunjang dalam aktivitas pembelajaran. Bagi seorang pendidik, guru maupun dosen, memahami dan terampil dalam memberdayakan informasi dan teknologi merupakan suatu keharusan. Sebab, kondisi saat ini memaksa kita tidak sebatas pada pengetahuan, juga keterampilan.

Berbagai platform turut mendukung dalam pelaksanaan pembelajaran dengan prinsip PAKIEM (Pembelajaran Aktif Kreatif Inovatif Efektif Menyenangkan), seperti: zoom meeting, google suite, microsoft education, dan sebagainya. Pelaksanan PAKIEM ini sangat diperlukan, baik saat pembelajaran daring maupun luring. Berbekal pengetahuan dan keterampilan menggunakan teknologi turut membantu dalam mensukseskan tujuan pembelajaran.

Selain itu, sumber-sumber pembelajaran saat ini juga mudah ditemukan sehingga berbagai kebutuhan materi dan informasi bisa dipenuhi. Dengan fasilitas yang ada, maka kreativitas pendidik dan peserta didik sangat diperlukan untuk membangun pembelajaran lebih baik.

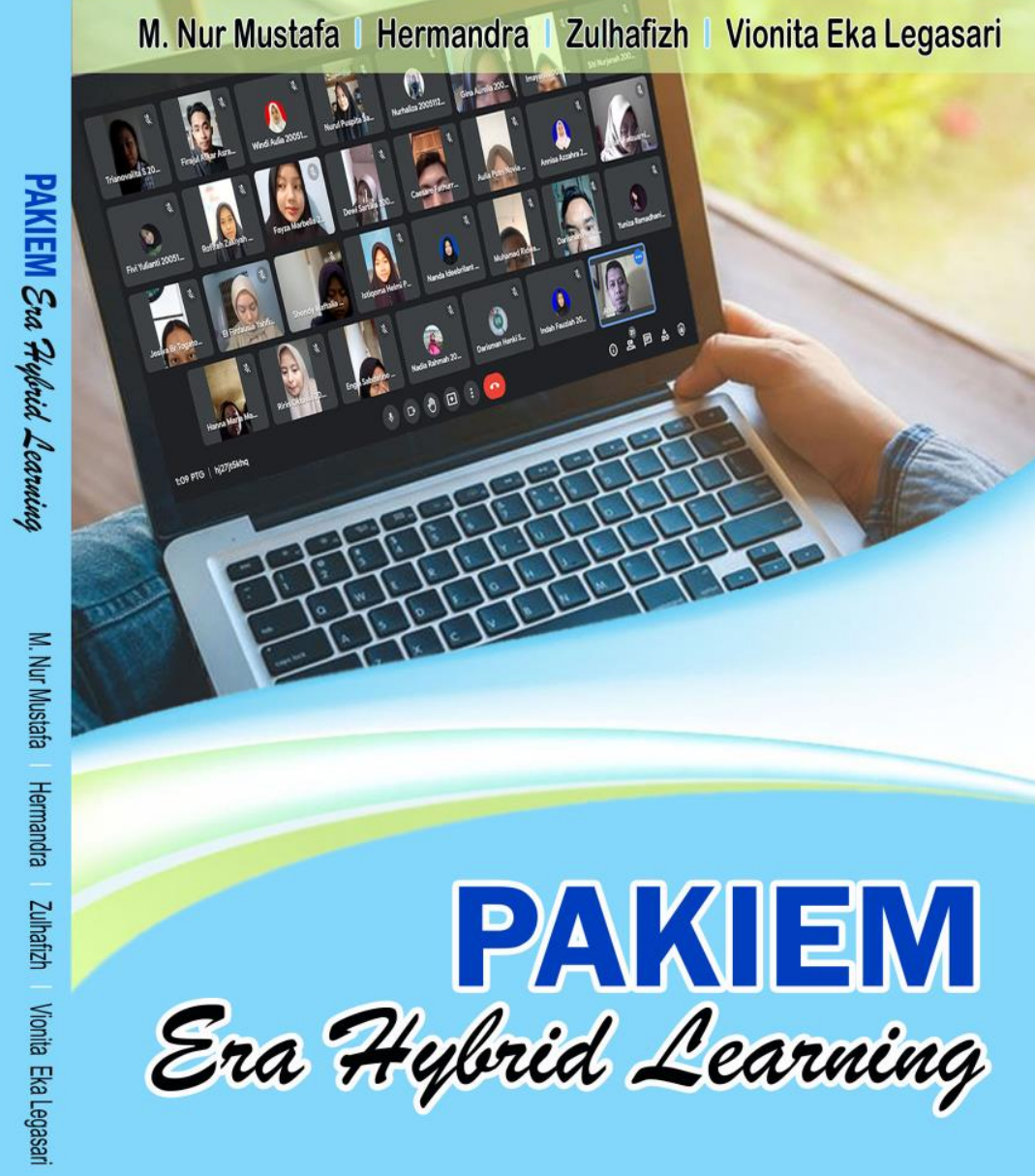





\section{PAKIEM \\ ERA HYBRID LEARNING}

M. Nur Mustafa

Hermandra

Zulhafizh

Vionita Eka Legasari 



\section{PAKIEM Era Hybrid Learning}

(C) M. Nur Mustafa, Hermandra, Zulhafizh, Vionita

Eka Legasari, 2021

Tata Letak: Zulhafizh

Desain Sampul:Zulhafizh

Cetakan pertama, November 2021

$\mathrm{xi}+124 \mathrm{hlm}$

$14,5 \times 20,5$

ISBN Cetak: 978-623-240-331-4

ISBN Digital: 978-623-240-332-1

Diterbitkan melalui:

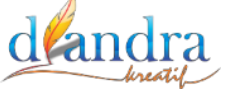

Anggota IKAPI (062/ DIY/ 08)

Jl. Melati No. 171 Sambilegi Baru Kidul,

Maguwoharjo, Depok, Sleman, Yogyakarta.

Telp. (0274) 2801996, Fax, (0274) 485222

Email: diandracreative@gmail.com

Facebook: http://www.facebook.com/diandrapenerbit

Instagram: @penerbitdiandra

Twitter: @bikinbuku

Website: www.diandracreative.com

Dicetak oleh:

Percetakan Diandra

Hak cipta dilindungi Undang-Undang.

All right reserved 


\section{KATA PENGANTAR}

Bersyukur kepada yang Sang Pemberi Rahmat, atas ridha-Nya dan bershalawat buat junjungan alam Rasulullah Sallallahu Alaihi Wassalam buku ini dapat diselesaikan. Buku ini berjudul PAKIEM Era Hybrid Learning. Isi buku berfokus pada hal-hal yang berkaitan dengan pembelajaran aktif, kreatif, inovatif, dan menyenangkan serta perangkat pendukung untuk pembelajaran di era abad 21 hybrid learnig.

Di era saat ini, pembelajaran tidak hanya sebatas lintas fisik saja, tetapi sudah merambah pada pemanfaatan teknologi sebagai penunjang dalam aktivitas pembelajaran. Bagi seorang pendidik, guru maupun dosen, memahami dan terampil dalam memberdayakan informasi dan teknologi merupakan suatu keharusan. Sebab, kondisi saat ini memaksa kita memiliki kerampilan yang tidak sebatas pada pengetahuan, juga keterampilan.

Berbagai platform turut mendukung dalam pelaksanaan pembelajaran dengan prinsip PAKIEM (Pembelajaran Aktif Kreatif Inovatif Efektif Menyenangkan), seperti: zoom meeting, google suite, microsoft education, dan sebagainya. Pelaksanan PAKIEM ini sangat diperlukan, baik saat pembelajaran daring maupun luring. Berbekal pengetahuan dan keterampilan menggunakan teknologi turut membantu dalam mensukseskan tujuan pembelajaran. Selain itu, sumbersumber pembelajaran saat ini juga mudah ditemukan 
sehingga berbagai kebutuhan materi dan informasi bisa dipenuhi. Dengan fasilitas yang ada, maka kreativitas pendidik dan peserta didik sangat diperlukan untuk membangun pembelajaran lebih baik.

Melalui kesempatan ini disampaikan kesemua pihak yang turut andil secara moril maupun materil tidak disebutkan satu persatu. Akhirnya, kritik dan saran dari berbagai pihak disambut dengan senang hati disertai terima kasih guna meningkatkan mutu buku dicetakan berikutnya. Semoga buku ini memberikan manfaat yang baik dan kepada Allah memohon ampun dan keselamatan. Amin.

Pekanbaru, November 2021

Penulis 


\section{DAFTAR ISI}

KATA PENGANTAR __ ii

DAFTAR ISI _

DAFTAR TABEL__ viii

DAFTAR GAMBAR _ ix

PETA KONSEP _

PENDAHULUAN _ 1

BAB I ESENSI PEMBELAJARAN ___ 4

A. Tujuan Pembelajaran _ 5

B. Materi_ 5

1. Pengertian Belajar _ 5

2. Hakikat Pembelajaran_ 7

3. Ciri-ciri Pembelajaran__ 8

4. Faktor-faktor Pembelajaran__ 10

C. Rangkuman__ 11

D. Evaluasi — 12

E. Daftar Pustaka__ 12

BAB II PEMBELAJARAN AKTIF _ 15

A. Tujuan Pembelajaran _ 15

B. Materi_ 15

1. Pengertian Pembelajaran Aktif___ 15

2. Ciri-ciri Pembelajaran Aktif__ 17

3. Dimensi dalam Pelaksanaan 
Pembelajaran Aktif

4. Faktor Pendukung dan Penghambat

5. Langkah-langkah Pembelajaran Aktif

C. Rangkuman

D. Evaluasi 26

E. Daftar Pustaka

A. Tujuan Pembelajaran

B. Materi

1. Pengertian Pembelajaran Kreatif 30

2. Ciri-ciri Pembelajaran Kreatif 32

3. Strategi Menghadirkan Pembelajaran Kreatif

4. Langkah-langkah Pembelajaran Kreatif

C. Rangkuman

D. Evaluasi

E. Daftar Pustaka

BAB IV PEMBELAJARAN INOVATIF

A. Tujuan Pembelajaran _ 41

B. Materi

1. Pengertian Pembelajaran Inovatif

2. Ciri-ciri Pembelajaran Inovatif

3. Strategi Menghadirkan Pembelajaran Inovatif

4. Prinsip Pengembangan Pembelajaran

C. Rangkuman

D. Evaluasi 
E. Daftar Pustaka

BAB V PEMBELAJARAN EFEKTIF

A. Tujuan Pembelajaran

B. Materi

1. Pengertian Pembelajaran Efektif 52

2. Ciri-ciri Pembelajaran Efektif 54

3. Keberhasilan Pembelajaran yang Efektif 57

4. Strategi Pembelajaran Efektif

C. Rangkuman 61

D. Evaluasi 62

E. Daftar Pustaka 62

BAB VI PEMBELAJARAN MENYENANGKAN

64

A. Tujuan Pembelajaran _ 65

B. Materi_ 65

1. Pengertian Pembelajaran Menyenangkan ___ 65

2. Ciri-ciri Pembelajaran Menyenangkan___ 68

3. Strategi Mewujudkan Pembelajaran

Menyenangkan

C. Rangkuman 71

D. Evaluasi 72

E. Daftar Pustaka 72

BAB VII GOOGLE SUITE

A. Tujuan Pembelajaran__ 75

B. Materi_ 75

1. Google Classroom__ 75

2. Google Form _ـ 83

3. Google Meet___ 89 
C. Rangkuman___ 90

D. Evaluasi__ 90

E. Daftar Pustaka ___ 91

BAB VIII MESIN PENCARI INFORMASI___ 92

A. Tujuan Pembelajaran ___ 93

B. Materi _ 93

1. Google Cendekia ___ 93

2. DOAJ _ 95

3. Portal Garuda __ 97

4. One Search Indonesia____ 98

C. Rangkuman __ 99

D. Evaluasi _ 100

E. Daftar Pustaka___ 101

GLOSARIUM _ 102

DAFTAR PUSTAKA _ 105

DAFTAR INDEKS _ 112

DATA PENULIS __ 117 


\section{DAFTAR TABEL}

Tabel 1. Dimensi dan Tujuan Pembelajaran Kreatif__ 34 Tabel 2. Langkah-langkah Pembelajaran Kreatif __ 36 


\section{DAFTAR GAMBAR}

Gambar 1. Komponen untuk Pembelajaran Inovatif _ 43

Gambar 2. Situs Google Classroom___ 76

Gambar 3. Pengguna Diarahkan untuk Memasukkan

Akun di Google Mail

Gambar 4. Tampilan Kelas di Google Classroom 78

Gambar 5. Tim Teaching di Google Classroom 79

Gambar 6. Menyapa, Menginformasikan Materi

Pembelajaran, dan Perintah Mengisi

Daftar Hadir

Gambar 7. Menginformasikan Kehadiran setelah

Selesai Pembelajaran

Gambar 8. Mengajak Peserta Didik untuk Diskusi/

Menyampaikan Pendapat

Gambar 9. Membagikan Materi Pembelajaran/Kasus Berupa Video

Gambar 10. Membagikan Materi Pembelajaran/Kasus Berupa Dokumen

Gambar 11. Membagikan Tugas/Kasus

Gambar 12. Membagikan Link Google Meet di Google Classroom

Gambar 13. Membuat Google Form melalui Google

Classroom

Gambar 14. Jika Memilih Tugasan 85

Gambar 15. Laman Isian Pembuatan Daftar Hadir 86 Gambar 16. Situs Google Drive 
Gambar 17. Tanda Titik Sembilan __ 87

Gambar 18. Pembuatan Form melalui Google Dive _ 88

Gambar 19. Copy Paste Link di Google Classroom _ 88

Gambar 20. Aktivitas Pembelajaran melalui Google Meet 89

Gambar 21. Tampilan Google Cendekia (Scholar) ___ 94 Gambar 22. Tampilan Hasil Penelusuran Google Cendekia — 94

Gambar 23. Tampilan DOAJ __ 96

Gambar 24. Tampilan Hasil Penelusuran DOAJ __ 96

Gambar 25. Tampilan Portal Garuda _ـ 97

Gambar 26. Tampilan Hasil Penelusuran Portal

Garuda 98

Gambar 27. Tampilan One Search Indonesia ___ 99

Gambar 28. Tampilan Hasil Penelusuran One Search Indonesia

99 


\section{PETA KONSEP}

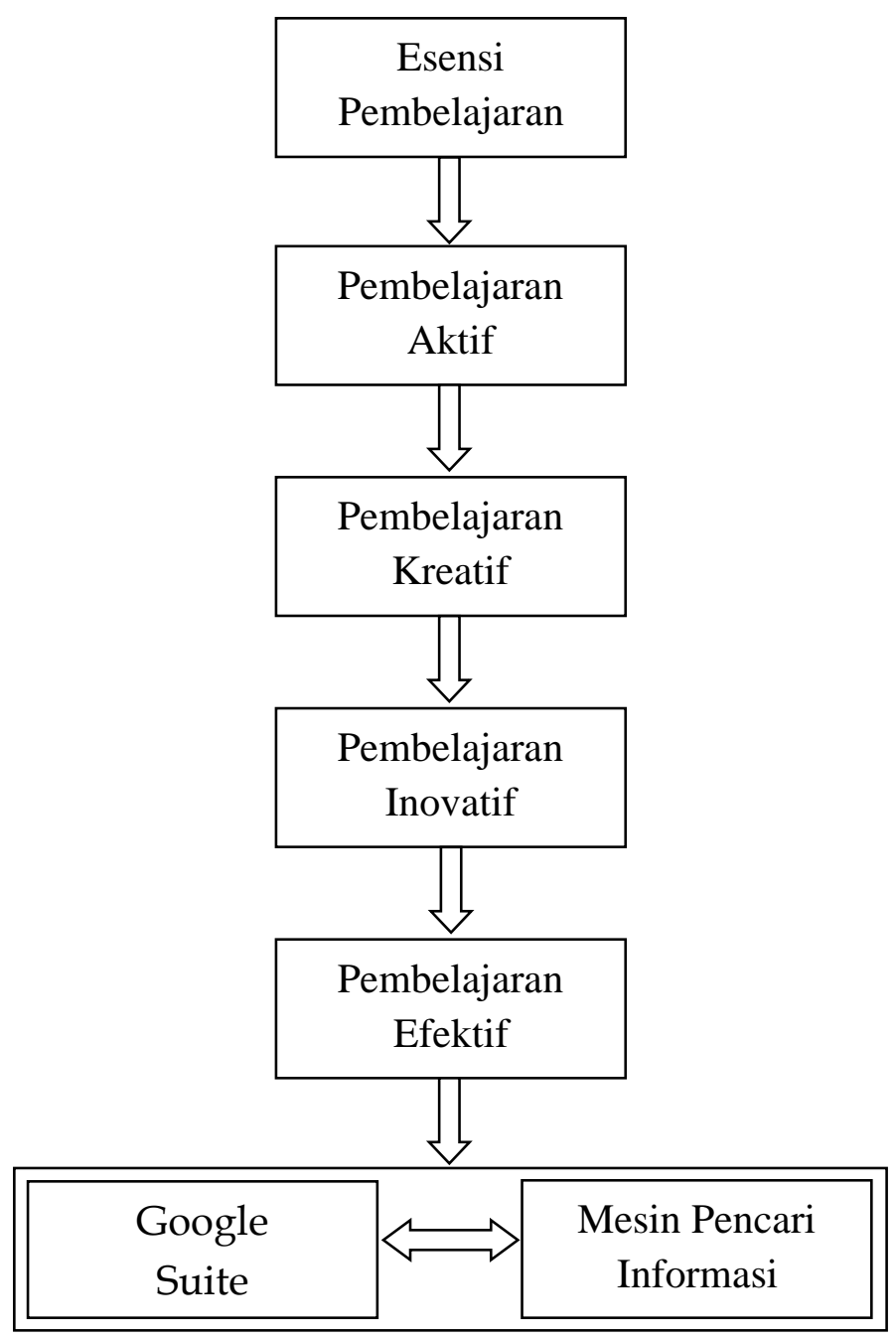





\section{PENDAHULUAN}

Pembelajaran bukanlah tindakan sederhana, tepi kompleks. Sebagai seorang pendidik memerlukan berbagai keterampilan agar pembelajaran yang dilakukan dapat mencapai tujuan yang diamanahkan dalam kurikulum. Pendidik perlu membekali diri dengan berbagai kompetensi agar dapat mewujudkan harapan pembelajaran yang ditartgetkan.

Sekurang-kurang ada empat kompetensi yang harus dimiliki pendidik, yaitu: kompetensi pedagogik, kompetensi kepribadian, kompetensi sosial, dan kompetensi profesional. Keempat kompetensi tersebut menjadi ikon untuk menghadirkan pendidik yang seutuhnya dan itu diperoleh melalui ketekunan dalam menjalankan profesi keguruannya. Artinya, kompetensikompetensi tersebut tidak bisa diperoleh secara spontan.

Dengan modal keempat kompetensi pendidik, sangat potensial seoarang pendidik mampu melahirkan pembelajaran yang disebut dengan istilah PAKIEM. PAKIEM kepanjangan dari Pembelajaran Aktif Kreatif Inovatif Efektif dan Menyenangkan. Upaya menghadirkan pembelajaran PAKIEM ini juga tidaklah sesederhana yang dipikirkan, karena untuk mewujudkan pendidik perlu membuat berbagai pertimbangan dengan menganalisis aspek AKIEM-nya. 
Terkait hal tersebut, bahan ajar ini berupaya menstimulus alur berpikir pendidik atau para calon pendidik dalam menghadirkan pembelajaran AKIEM. Sebagai pendidik maupun calon pendidik harus memahami dengan baik esensi PAKIEM terebut. Maka bahan ajar ini pula dibagi beberapa bagian bab agar uraian atau pembahasannya lebih mendalam.

Terkait pemberdayaan bahan ajar ini dalam pembelajaran, tentunya setiap pendidik bisa menyesuaikan edisi pertemuan dalam pembelajaran. Bahana ajar ini bisa saja dirancang dalam pembelajaran untuk satu kali pertemuan ataupun beberapa pertemuan. Satu kali pertemuan manakala calon pendidik yang memahami bahan ajar ini sudah memiliki modal terlebih dahulu pada pelajaran lain yang berhubungan dengan PAKIEM. Maka, yang diperlukan adalah berfokus pada pemberdayaan perangkat e-learning.

Sementara itu, jika calon pendidik yang mempelajari bahan ajar ini belum mememiliki bekal terkait dengan PAKIEM tersebut, maka materi pertemuan dapat disesuaikan dengan jumlah BAB pembahasan. Bahan ajar ini terdiri delapan $\mathrm{BAB}$ pembahasan. $\mathrm{BAB}$ satu membahas esensi pembelajaran, $\mathrm{BAB}$ dua membahas pembelajaran aktif, BAB tiga membahas pembelajaran kreatif, BAB empat membahas pembelajaran inovatif, BAB lima membahas pembelajaran efektif, dan $\mathrm{BAB}$ enam membahas pembelajaran menyenangkan.

Khusus BAB tujuh membahas google suite dengan fokus google classroom, google form, dan google meet. 
Sementara itu, BAB delapan membahas tentang mesin pencari informasi: googel scholar, DOAJ, portal garuda, dan one search Indonesia. Pada kontek ini, Dua BAB terakhir ini dihadirkan sebagai fasilitas yang potensial digunakan untuk pembelajaran di abad 21. Apalagi kondisi saat ini sedang pendemi Covid 19 yang menuntut pendidik melaksankan proses belajar mengajar tidak tatap muka atau lebih dikenal dengan istilah pembelajaran daring (dalam jaringan).

Kombinasi perangkat atau yang ada dapat membantu pendidik untuk tetap melaksanakan pembelajaran AKIEM dengan basis internet. Kemudian didukung pula website yang bisa dijadikan dasar dalam mencari informasi seperti disebutkan pada paragraf sebelumnya. Hal ini diperlukan agar pendidik ketika menjalankan tugasnya tidak kekurangan bahan ajar. Demikian pula sebaliknya, para calon pendidik atau peserta didik dapat memaksimalkan dalam mencari informasi agar tidak kekurangan ilmu pengetahuan dan wawaasan.

Pada kegiatan akhir yang diharapkan pada calon pendidik yang memahami bahan ajar ini diharapkan dapat memberikan kompetensi tentang cara menghadirkan pembelajaran AKIEM walaupun cara daring. Selain itu, dengan latihan rutin dalam merancang pembelajaran AKIEM, sangat potensial akan melahirkan calon pendidik yang mampu merancang pembelajaran AKIEM walaupun di era hybrid learning atau secara daring. 


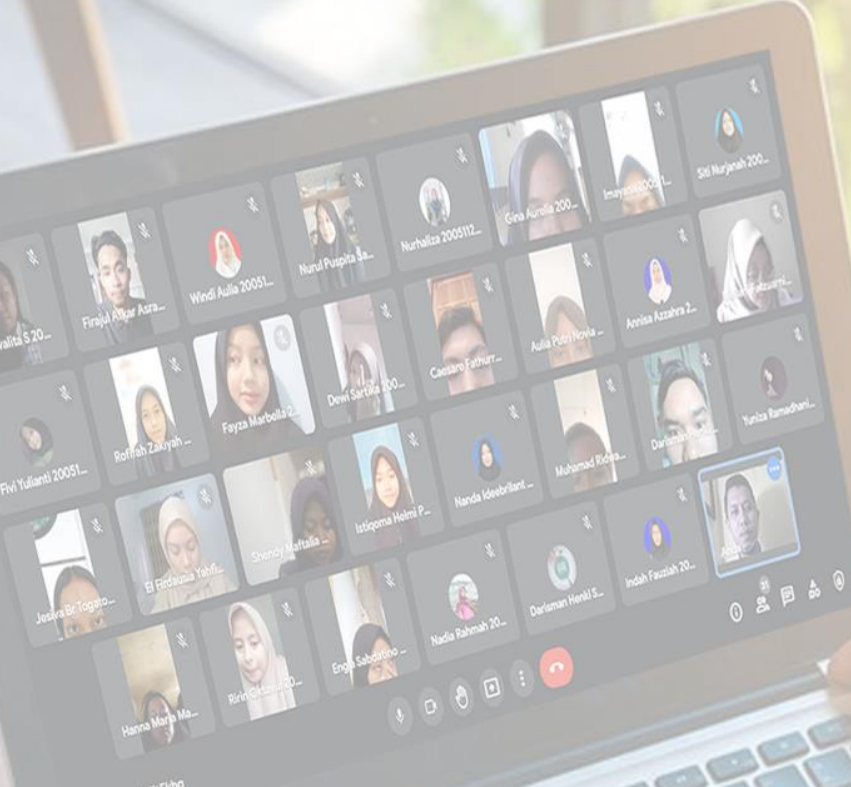

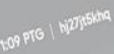

BAB I

ESENSI PEMBELAJARAN 


\section{A. Tujuan Pembelajaran}

Ada beberapa tujuan pembelajaran yang berkait dengan topik esensi pembelajaran, yaitu:

1. Menjelaskan pengertian belajar

2. Menguraikan hakikat pembelajaran

3. Menguraikan ciri-ciri pembelajaran

4. Menganalisis faktor-faktor pembelajaran

\section{B. Materi}

\section{Pengertian Belajar}

Belajar dimaknai sebagai proses perubahan perilaku sebagai hasil interaksi individu dengan lingkungannya. Perubahan perilaku terhadap hasil belajar bersifat berkelanjutan, positif, aktif, dan terarah. Karena positif dan terarah maka aktivitas belajar sesungguhnya terjadi dari aktivitas yang sadar dan disengaja. Dalam kondisi ini akan terjadi aktivitas mental atau psikologis pada individu yang belajar.

Hal ini sejalan dengan penjelasan Aunurrahman (2016) bahwa belajar merupakan suatu proses yang dilakukan individu untuk memperoleh suatu perubahan tingkah laku yang baru secara keseluruhan, sebagai hasil pengalaman individu itu sendiri di dalam interaksi dengan lingkungannya. Menurut Budiningsih (2005) belajar merupakan suatu proses pembentukan pengetahuan, yang mana peserta didik aktif melakukan kegiatan, aktif berpikir, menyusun konsep, dan memberi makna tentang hal-hal yang sedang dipelajari. 
Ikhsan (2016) belajar sebagai suatu proses yang kompleks yang terjadi pada diri setiap orang sepanjang hidupnya. Proses belajar itu terjadi karena adanya interaksi antara sesorang dengan lingkungannya. Maka, belajar dapat terjadi kapan saja dan dimana saja. Salah satu pertanda bahwa sesorang itu telah belajar adalah adanya perubahan tingkah laku pada diri orang itu yang mungkin disebabkan oleh terjadinya perubahan pada tingkat pengetahuan, keterampilan, atau sikapnya.

Maswan \& Muslimin (2011) memaknai belajar adalah segenap rangkaian kegiatan atau aktivitas yang dilakukan secara sadar oleh seseorang dan mengakibatkan perubahan dalam dirinya berupa penambahan pengetahuan atau kemahiran berdasarkan alat indra dan pengalamannya. Apabila setelah belajar peserta didik tidak ada perubahan tingkah laku yang positif maka aktivitas belajarnya belum maksimal atau belum sempurna. Kemudian Siregar dan Nara (2012) memberikan penguatan terhadap makna belajar merupakan sebuah proses yang kompleks yang terjadi pada semua orang dan berlangsung seumur hidup, sejak masih bayi (bahkan dalam kandungan) hingga liang lahat.

Bertolok dari banyaknya pengertian belajar dapat dipahami bahwa belajar pada hakekatnya merupakan proses kegiatan secara berkelanjutan dalam rangka perubahan perilaku peserta didik secara konstruktif dalam kurun sepanjang hayat yang berlandaskan kesadaran dan terencana atau terarah. Hal ini diperkuat dengan Undangundang Sistem Pendidikan Nasional Nomor 20 Tahun 
2003 yang menyatakan pendidikan adalah usaha sadar dan terencana untuk mewujudkan suasana belajar dan proses pembelajaran agar peserta didik secara aktif mengembangkan potensi dirinya untuk memiliki kekuatan spiritual keagamaan, pengendalian diri, kepribadian, kecerdasan, dan akhlak mulia, serta keterampilan yang diperlukan dirinya, masyarakat bangsa, dan negara.

\section{Hakikat Pembelajaran}

Pembelajaran merupakan suatu proses interaksi antara peserta didik dengan pendidik dan berbagai sumber belajar yang ada di lingkungan belajar tersebut. Hamdani (2011) pembelajaran adalah usaha pendidik membentuk tingkah laku yang diinginkan dengan menyediakan lingkungan atau stimulus. Langkah ini bertujuan untuk membantu peserta didik. Seperti dikatakan Warsita (2008) bahwa pembelajaran adalah suatu sistem yang bertujuan untuk membantu proses belajar peserta didik, yang berisi serangkaian peristiwa yang dirancang, disusun sedemikian rupa untuk mempengaruhi dan mendukung terjadinya proses belajar peserta didik yang bersifat internal.

Untuk mencapai harapan dari kegiatan pembelajaran, pendidik harus memiliki program yang disusun secara instruksional dan mendorong peserta didik untuk belajar secara aktif. Aktivitas pembelajaran yang aktif akan membawa peserta didik untuk memperluas wawasan. Ainurrahman (2016) bahwa interaksi peserta didik dengan pendidik yang didukung dengan sumber belajar dapat membantu peserta didik memperoleh ilmu dan 
pengetahuan, penguasaan, kemahiran, serta pembentukan sikap, dan kepercayaan dan sebagainya. Maka pembelajaran merupakan suatu tindakan bantuan yang diberikan kepada peserta didik dalam memenuhi kebutuhan belajarnya.

Atas dasar hal tersebut, maka esensi pembelajaran terbentuk karena adanya tujuan yang ingin dicapai, bahan/materi pembelajaran, pendidik, peserta didik, dan sarana dan prasarana. Menurut Sardiman (2010) terpenuhinya bagian-bagian atau komponen pembelajaran akan mengoptimalkan aktivitas yang dilakukan. Sebaliknya, salah satu dintara komponen itu tidak terpenuhi dengan baik baik dan terencana maka akan berdampak pula pada aktivitas yang dilakukan dalam pembelajaran.

\section{Ciri-ciri Pembelajaran}

Hamdani (2011) berpendapat bahwa kegiatan pembelajaran memiliki ciri-ciri:

a. kegiatan yang dilakukan secara sadar dan direncanakan dengan sistematis;

b. menumbuhkan perhatian dan motivasi peserta didik dalam belajar;

c. menyediakan bahan belajar yang menarik perhatian dan menantang;

d. dapat menggunakan alat bantu belajar yang tepat dan menarik, menciptakan suasana belajar yang aman dan menyenangkan; 
e. membuat peserta didik siap menerima pelajaran, baik secara fisik maupun secara psikologi;

f. menekankan keaktifan peserta didik;

Dalam perspektif Putra (2013), ia melihat bahwa ciriciri pembelajaran terletak pada adanya unsur dinamis dalam proses belajar peserta didik, yakni motivasi belajar, bahan belajar, alat bantu belajar, suasana belajar, dan kondisi subjek belajar.

a. Motivasi belajar. Dalam kegiatan pembelajaran, peserta didik yang tidak dapat melakukan tugas pembelajaran perlu diupaya untuk menemukan sebabsebabnya, kemudian mendorong peserta didik tersebut agar berkenan menyelesaikan tugas. Artinya, peserta didik perlu diberikan ransangan agar memilikki semangat atau hasrat untuk mealkukan sesuatu;

b. Bahan belajar. Bahan belajar merupakan isi dalam pembelajaran yang terkait dengan fakta, prinsip, dan konsep yang diperlukan untuk mencapai tujuan pembelajaran;

c. Alat bantu/media belajar. Alat yang bisa membantu peserta didik dalam belajar untuk mencapai tujuan belajar;

d. Suasana belajar. Suasana belajar sangat penting dan akan berpengaruh terhadap pencapaian tujuan pembelajaran. Hubungan timbal balik yang berlangsung dengan semangat dan gembira dapat menghadirkan aktivitas pembelajaran berlangsung baik dalam mencapai tujuan pembelajaran; 
e. Kondisi peserta didik yang belajar. Setiap peserta didik memiliki sifat yang unik atau berbeda, tetapi juga mempunyai kesamaan, yaitu langkah-langkah perkembangan dan potensi yang perlu diaktualisasi melalui pembelajaran. Kondisi peserta didik yang demikian dapat berpengaruh terhadap partisipasinya dalam proses belajar. Untuk itu, kegiatan pembelajaran lebih menekankan pada peranan dan partisipasi peserta didik, bukan peran guru yang dominan, tetapi lebih berperan sebagai fasilitator, motivator, dan pembimbing.

\section{Faktor-faktor Pembelajaran}

Adapun berpendapat faktor-faktor yang dalam suatu kegiatan pembelajaran yaitu:

a. Peserta didik adalah seseorang yang bertindak sebagai pencari, penerima, dan menyimpan isi pelajaran yang dibutuhkan untuk mencapai tujuan.

b. Pendidik adalah seseorang yang bertindak sebagai pengelola kegiatan belajar mengajar, katalisator belajar mengajar, dan peranan lainnya yang memungkinkan berlangsungnya kegiatan belajar mengajar yang efektif.

c. Tujuan yakni, pernyataan tentang perubahan perilaku yang diinginkan terjadi pada peserta didik setelah mengikuti belajar mengajar. Perubahan perilaku tersebut mencakup perubahan kognitif, psikomotor dan afektif. 
d. Isi pelajaran yakni, segala informasi berupa fakta, prinsip dan konsep yang diperlukan untuk mencapai tujuan.

e. Metode yakni, cara yang teratur untuk memberikan kesempatan kepada peserta didik untuk mendapatkan informasi yang dibutuhkan peserta didik untuk mencapai tujuan.

f. Media yakni, bahan pengajaran dengan atau tanpa peralatan yang digunakan untuk menyajikan informasi kepada peserta didik agar dapat mencapai tujuan.

g. Evaluasi yakni, cara tertentu yang digunakan untuk menilai suatu proses dan hasilnya. Evaluasi dilakukan terhadap seluruh komponen kegiatan pembelajaran dan sekaligus memberikan balikan bagi setiap komponen kegiatan (Gino et al, 1998).

\section{Rangkuman}

Belajar merupakan proses perubahan perilaku sebagai hasil interaksi individu dengan lingkungannya yang dilakukan secara sadar dan disengaja. Harapan dari belajar adalah memiliki kekuatan spiritual keagamaan, pengendalian diri, kepribadian, kecerdasan, dan akhlak mulia, serta ketermpilan yang diperlukan dirinya, masyarakat bangsa, dan negara. Sementara pembelajaran merupakan suatu proses interaksi antara peserta didik dengan pendidik dan berbagai sumber belajar yang ada di lingkungan belajar tersebut. Dalam kegiatan pembelajaran, erat hubungannnya dengan yakni motivasi belajar, bahan belajar, alat bantu belajar, suasana belajar, dan kondisi 
subjek belajar. Bagian-bagian tersebut turut mempengaruhi aktivitas belajar dan pembelajaran

\section{Evaluasi}

Setelah mempelajari dan memahami materi esensi pembelajaran, jawablah pertanyaan berikut:

1. Jelaskan pengertian belajar!

2. Uraikanlah hakikat pembelajaran!

3. Uraikanlah ciri-ciri pembelajaran!

4. Analisislah faktor-faktor yang mempengaruhi pembelajaran di kelas!

\section{E. Daftar Pustaka}

Ainurrahman. (2016). Belajar dan Pembelajaran. Bandung: Alfabeta.

Budiningsih, Asri. 2005. Belajar dan Pembelajaran. Jakarta: Rineka Cipta.

Gino, H. J., dkk. (1998). Belajar dan Pembelajaran II. Surakarta: UNS.

Hamdani. (2011). Strategi Belajar Mengajar. Bandung: Pustaka Setia.

Ikhsan, M. (2016). Media Pembelajaran Berhitung untuk Madrasah Ibtidaiyah Rahmatullah Kota Jambi. Jurnal Akademika, 9(1-2), 55-61.

Maswan \& Muslimin, K. (2017). Teknologi Pendidikan. Yogyakarta: Pustaka Pelajar.

Putra, S. R. (2013). Desain Belajar Mengajar Kreatif Berbasis Sains. Jogjakarta: Diva Press. 
Sadirman, A. M. (2010). Interaksi dan Motivasi Belajar Mengajar. Jakarta: Raja Grafindo Persada.

Siregar, E., \& Nara, H. (2012). Teori Belajar dan Pembelajaran. Bogor: Ghalia Indonesia.

Undang-undang Nomor 20 Tahun 2003 tentang Sistem Pendidikan Nasional.

Warsita, B. (2008). Teknologi Pembelajaran Landasan dan Aplikasinya. Jakarta: Rineka Cipta. 


\section{GLOSARIUM}

Belajar

Proses kegiatan secara berkelanjutan dalam rangka perubahan perilaku peserta didik secara konstruktif dalam kurun sepanjang hayat yang berlandaskan kesadaran dan terencana atau terarah.

\section{DOAJ}

Kependekan dari Directory of Open Access Journal merupakan mesin yang mengindeks publikasi ilmiah yang diterbitkan oleh jurnal-jurnal ilmiah.

Evaluasi

Cara tertentu yang digunakan untuk menilai suatu proses.

Google cendekia

Sebuah mesin yang memfasilitas dalam pencarian publikasi ilmiah seperti artikel jurnal, artikel prosiding, buku, skripsi/tesis, dan sebagainya.

Google classrom

Layanan berbasis internet atau web. Para pendidik bisa menyampaikan materi, tugas, penilaian, dan evaluasi melalui fasilitas tersebut sehingga aktivitas pembelajaran tetap bisa berlangsung.

Google form

Sebuah fasilitas dari google yang bisa digunakan untuk pembuatan daftar hadir pembelajaran, sarana memberikan tanggapan, dan sarana evaluasi. 
Google meet

Fasilitas yang disediakan google yang memungkinkan penggunanya bisa melakukan konferensi atau bertatap mula secara virtual.

One Search Indonesia

Mesin pencarian data atau informasi hasil publikasi, baik bersifat ilmiah maupun non ilmiah .

Pembelajaran

Suatu proses interaksi antara peserta didik dengan pendidik dan berbagai sumber belajar yang ada di lingkungan belajar tersebut.

Pembelajaran aktif

Suatu kegiatan belajar mengajar yang dikelola dan didesain dengan membuka ruang kepada peserta didik untuk kreatif dan aktif dalam berbagai aktifitas belajar.

Pembelajaran efektif

Kegiatan belajar dan mengajar berlangsung secara interaktif dan terbentuknya suasana belajar yang nyaman.

Pembelajaran inovatif

Sebuah tindakan yang mendorong dan berupaya membangun belajar mengajar lebih baik dari sebelumbnya, dalam artian mampu menciptakan berbagai terobosan yang dapat memberikan makna pada peserta didik.

Pembelajaran kreatif

Suatu tindakan yang menekankan tentang upaya pendidik dalam memfasilitasi kegiatan belajar 
sehingga suasana belajar dapat berlangsung dengan kondusif dan nyaman serta mampu merangsang peserta didik untuk melakukan berbagai kegiatankegiatan kreatif dan menyenangkan.

Pembelajaran menyenangkan

Suatu strategi yang digunakan untuk menciptakan lingkungan belajar yang efektif, menerapkan kurikulum, menyampaikan materi atau informasi, dan memudakan proses pembelajaran dengan memperhatikan tujuan yang ingin dicapai.

\section{Pendidik}

Seseorang yang bertindak sebagai pengelola kegiatan belajar mengajar, katalisator belajar mengajar, dan peranan lainnya yang memungkinkan berlangsungnya kegiatan belajar mengajar yang efektif.

Peserta didik

Seseorang yang bertindak sebagai pencari, penerima, dan menyimpan isi pelajaran.

Portal garuda

Sebuah sistem mengindeks banyak artikel baik berupa artikel jurnal maupun hasil prosiding seminar. 


\section{DAFTAR PUSTAKA}

Ahmadi, A., \& Prasetya, J. T. (1997). Strategi Belajar

Mengajar. Bandung: Pustaka Setia.

Ainurrahman. (2016). Belajar dan Pembelajaran. Bandung:

Alfabeta.

Asmani, J. M. (2011). 7 Tips Aplikasi PAKEM. Yogjakarta: DIVA press.

Berk, L. E. (1998). Development Through the Lifespan. United Kingdom: Pearson.

Bistari, B. (2017). Konsep dan Tujuan Pembelajaran Efektif.

Jurnal Kajian Pembelajaran dan Keilmuan, 1(2), 13-20.

Bonwell, C. C., \& Eison, J. A. (1991). Active Learning:

Creating Excitement in the Classroom. 1991 ASHEERIC Higher Education Reports. ERIC Clearinghouse on Higher Education, The George Washington University, One Dupont Circle, Suite 630, Washington, DC 20036-1183.

Budiningsih, Asri. 2005. Belajar dan Pembelajaran. Jakarta: Rineka Cipta.

Darmansyah. (2010). Strategi Pembelajaran Menyenangkan dengan Humor. Jakarta: Bumi Aksara.

DePorter, B., Reardon, M., \& Singer-Nourie, S. (1999).

Quantum Teaching: Mempraktikkan Quantum Learning di Ruang-ruang Kelas (terjemahan Ary Nilandari). Bandung: Kaifa.

Dryden, G., \& Vos, J. (2003). The Learning Revoluton. Bandung: Kaifa.

Fakhrurrazi, F. (2018). Hakikat Pembelajaran yang Efektif. At-Tafkir, 11(1), 85-99. 
French, R., Imms, W., \& Mahat, M. (2020). Case Studies on the Transition from Traditional Classrooms to Innovative Learning Environments: Emerging Strategies for Success. Improving Schools, 23(2), 175189.

Gino, H. J., dkk. (1998). Belajar dan Pembelajaran II. Surakarta: UNS.

Grabinger, R. S., \& Dunlap, J. C. (1995). Rich Environments for Active Learning: A Definition. ALT-J, 3(2), 5-34.

Hamdani. (2011). Strategi Belajar Mengajar. Bandung: Pustaka Setia.

Harahap, D. P. (2014). Supervisi Akademik Teknik Workshop Meningkatkan Kemampuan Guru Melaksanakan Pembelajaran Aktif. Jurnal Manajemen Pendidikan Indonesia, 6(02), 67-76.

Ikhsan, M. (2016). Media Pembelajaran Berhitung untuk Madrasah Ibtidaiyah Rahmatullah Kota Jambi. Jurnal Akademika, 9(1-2), 55-61.

Indrawati et al. 2009. Pembelajaran Aktif, Kreatif, Efektif, dan Menyenangkan untuk Guru SD. Jakarta: PPPPTK IPA. Joyce, B., \& Weil, M. (1980). Models of Teaching (Second Edition). Englewood Cliffs, New Jersey: PrenticeHall, Inc.

Machmudah, U. (2008). Active Learning dalam Pembelajaran Bahasa Arab. Malang : UIN Malang Press.

Ma'ruf, M. W., \& Syaifin, R. A. (2021). Strategi Pengembangan Profesi Guru dalam Mewujudkan Suasana Pembelajaran yang Efektif. Al-Musannif, $3(1), 27-44$. 
Maswan \& Muslimin, K. (2017). Teknologi Pendidikan. Yogyakarta: Pustaka Pelajar.

Morris. W. (2006). Creativity-Its Place in Education. http://jpb.com/creative/Creativity_in_Education. pdf

Muriyatmoko, D. (2018). Pengaruh Indeksasi DOAJ terhadap Sitasi pada Jurnal Terakreditasi Sinta Menggunakan Analisis Regresi Linier. Jurnal Simantec, 7(1), 31-38.

Mustafa, M. N., Hermandra, \& Zulhafizh. (2018). Strategi Inovatif: Gaya Guru Sukses dalam DuniaPendidikan. Bandung: Diandra Kreatif.

Mustafa, M. N., Hermandra, \& Zulhafizh. (2019). Teachers' Strategies to Design Media to Implement

Communicative Leaning in Public Schools. Journal of Educational Sciences, 3(1), 13-24.

Mustafa, M. N., Hermandra, \& Zulhafizh. (2020). Pengelolaan Kelas: Upaya Meningkatkan Kualitas Pembelajaran. Yogyakarta: Mirra Buana Media.

Mustafa, M. N., Hermandra, Suarman, \& Zulhafizh. (2019). Manajerial Pembelajaran Kreatif: Menjadi Guru Jitu. Yogyakarta: Mirra Buana Media.

Mustafa, M. N., Hermandra, Zulhafizh, \& Hermita, N. (2018). The Significance of Language Motivation Learning: Correlation Analysis. Advanced Science Letters, 24(11), 8380-8383.

Nurdyansyah, N., \& Andiek, W. (2015). Menejemen Sekolah Berbasis ICT. Sidoarjo: Nizamia Learning Center. 
Nurjan, S. (2018). Pengembangan Berpikir Kreatif. $A L-$ ASASIYYA: Journal of Basic Education, 3(1), 105-116.

Nurrita, T. (2018). Pengembangan Media Pembelajaran untuk Meningkatkan Hasil Belajar Siswa. MISYKAT: Jurnal Ilmu-ilmu Al-quran, Hadist, Syari'ah dan Tarbiyah, 3(1), 171-210.

Orlando, M. (2013). Nine Characteristics of a Great Teacher. https://www.facultyfocus.com/articles/philosoph y-of-teaching/nine-characteristics-of-a-great teacher/

Oya, R. N., \& Budiningsih, C. A. (2014). Peningkatkan Motivasi dan Hasil Belajar Bahasa Indonesia Menggunakan Model Pembelajaran Kreatif dan Produktif. Jurnal Prima Edukasia, 2(1), 116-126.

Putra, S. R. (2013). Desain Belajar Mengajar Kreatif Berbasis Sains. Jogjakarta: Diva Press.

Reigeluth, C. M. (1983). Instructional Design Theories and Models: An Overview of Their Current Status. London: Lawrence Erlbaum Associates, Inc.

Sadirman, A. M. (2010). Interaksi dan Motivasi Belajar Mengajar. Jakarta: Raja Grafindo Persada.

Sagala, S. (2013). Kemampuan Profesional Guru dan Tenaga Kependidikan. Bandung: Alfabeta.

Sani, R. A. (2013). Inovasi Pembelajaran. Jakarta: Bumi Aksara.

Sevima.Com. (2020). 5 Inovasi untuk Model Pembelajaran yang Lebih Efektif. https://sevima.com/5-inovasiuntuk-model-pembelajaran-yang-lebih-efektif/ $(29 / 7 / 2021)$ 
Silbermen, M. (1996). Active Learning: 101 Strategies to Teach Any Subject. Jakarta: Yapendis.

Siregar, E., \& Nara, H. (2012). Teori Belajar dan Pembelajaran. Bogor: Ghalia Indonesia.

Suherman, E., et all. (2003). Strategi Pembelajaran Matematika Kontemporer. Bandung: UPI.

Suwarsito, S., \& Harjono, H. (2010). Pemanfaatan Edukasinet dalam Pencarian Sumber Belajar melalui Akses Internet. JUITA: Jurnal Informatika, 1(2), 59 - 63

Syaparuddin, S., Meldianus, M., \& Elihami, E. (2020).

Strategi Pembelajaran Aktif dalam Meningkatkan Motivasi Belajar PKn Peserta Didik. Mahaguru: Jurnal Pendidikan Guru Sekolah Dasar, 1(1), 30-41.

Syofyan, H., \& Ismail, I. (2018). Pembelajaran Inovatif dan Interaktif dalam Pembelajaran IPA. Qardhul Hasan: Media Pengabdian Kepada Masyarakat, 4(1), 65-75.

Trinova, Z. (2012). Hakikat Belajar dan Bermain Menyenangkan bagi Peserta Didik. Al-Ta Lim Journal, 19(3), 209-215.

Undang-undang Nomor 20 Tahun 2003 tentang Sistem Pendidikan Nasional.

Uno, H. B., \& Mohamad, N. (2011). Belajar dengan Pendekatan PAILKEM. Jakarta: Bumi Aksara.

Utami, R. (2019). Analisis Respon Mahasiswa terhadap Penggunaan Google Classroom pada Mata Kuliah Psikologi Pembelajaran Matematika. In Prisma, Prosiding Seminar Nasional Matematika, 2, pp. 498-502. Warsita, B. (2008). Teknologi Pembelajaran Landasan dan Aplikasinya. Jakarta: Rineka Cipta. 
Wena, M. (2009). Strategi Pembelajaran Inovatif Kontemporer. Jakarta: Bumi Aksara.

Wulandari, D. (2016). Model Pembelajaran yang Menyenangkan Berbasis Peminatan. Jurnal Inspirasi Pendidikan, 6(2), 851-856.

Zulhafizh \& Permatasari, S. (2020). Developing Quality of Learning in the Pandemic Covid-19 Through Creative and Critical Thinking Attitudes. JURNAL PAJAR (Pendidikan dan Pengajaran), 4(5), 937-949.

Zulhafizh, Atmazaki, \& Syahrul, R. (2013). Kontribusi Sikap dan Motivasi Belajar Siswa terhadap Hasil Belajar Bahasa Indonesia. Jurnal Bahasa, Sastra dan Pembelajaran, 1(2), 13-28.

Zulhafizh. (2020). Orientation on Implementation of Learning Curriculum at Senior High School: Teacher's Perspective. Jurnal PAJAR (Pendidikan dan Pengajaran), 4(2), 303-315.

Zulhafizh. (2021). Peran dan Mutu Pelaksanaan Pembelajaran oleh Guru di Satuan Pendidikan Tingkat Atas. Jurnal Kependidikan: Jurnal Hasil Penelitian dan Kajian Kepustakaan di Bidang Pendidikan, Pengajaran dan Pembelajaran, 7(2), 328339.

Zulhafizh. (2021, Agustus 2021). Membuat dan Bergabung

Di Kelas Google Classroom + Meet. [Youtube]. https://youtu.be/AA9U0FNYg3o

Zulhafizh. (2021, September 4). Tujuh Situs yang Wajib Akademisi dan Praktisi Ketahui 
PAKIEM Era Hybrid Learning

Saat Menulis Karya Ilmiah. [Youtube].
https://youtu.be/e0rDX_24xQ

Situs:

https://garuda.ristekbrin.go.id/.

https://youtu.be/QDDXVN8iupI

www.doaj.org

https://onesearch.id/ 


\section{DAFTAR INDEKS}

\section{A}

abad, ii, 13, 86

Ahmadi, 30, 37, 116

Ainurrahman, 17, 22, 116

ajar, 11, 12, 13, 26, 31

akhlak, 17, 21

Aktif, iv, v, 11, 25, 27, 29, 33, 38,

$66,84,117,120$

aktivitas, ii, 15, 16, 18, 20, 22, 25, $26,27,28,30,31,32,35,36,40$, $41,43,44,46,48,51,52,56,57$, $58,65,66,67,68,69,70,71,76$, $80,81,82,86,89,90,94,101$, 113

antusias, 42

artikel prosiding, 104, 110, 113

awal, 132

B

bahan ajar, 12, 26

bahasa, 35, 37

bangsa, 17, 21, 57

Berk, 77, 84, 116

berkreasi, 27, 53, 58

berpikir, 11, 15, 25, 28, 42, 47, 52,

$53,56,58$

berpotensi, 45

Bistari, 63, 73, 116

Bloom, viii, ix

Bonwell, 27, 38, 116

Budiningsih, 15, 22, 42, 47, 49, 116, 119 buku, ii, iii, 26, 31, 104, 109, 110, 113,133

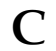

covid 19, 86, 100

Covid 19, 13

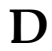

daring, ii, 13, 36, 37, 86, 87, 100

Darmansyah, 77, 84, 116

Deporter, 77

Desain, i, 44

Disiplin, 45

DOAJ, vii, 12, 104, 106, 107, 111, $112,113,118$

Domain, viii, ix

dominan, 20, 27

Dryden, 76, 84, 116

dunia, 128

Dunlap, 25, 38, 117

E

efektif, 12, 20, 29, 37, 43, 54, 60, 62, $63,64,66,67,69,70,72,77,78$, $82,114,115,120$

Efektif, vi, 11, 60, 62, 64, 67, 69, 73, $84,116,117,118,120$

Eison, 27, 38, 116

emosional, 42, 56

episode, 79

esensi, 12, 15, 18, 22, 77 
evaluasi, 35, 47, 48, 54, 58, 64, 72, $86,94,95,97,101,113$

Evaluasi, iv, v, vi, vii, 21, 22, 34, $37,47,48,59,72,83,101,111$, 113

\section{F}

Fakhrurrazi, 62, 63, 67, 69, 73, 117 fase, 33,34

fleksibel, 79

fungsional, 70

\section{G}

gigih, 45

googel scholar, 12

google, ii, 12, 86, 87, 89, 90, 94, 95,

97, 100, 101, 104, 105, 110, 111,

113,114

google classrom, 86, 89, 95, 101

google form, 12, 86, 94, 101

google meet, ii, 12, 86, 90, 100, 101

google suite, 12, 86, 101

Grabinger, 25, 38, 117

gratis, $87,100,106,111$

\section{$\mathbf{H}$}

Hamdani, 17, 18, 22, 117

Harjono, 32, 38, 120

hebat, 78,79

hybrid learning, 13, 86, 101, 104, 111

\section{I}

Ikhsan, 16, 22, 117

ikon, 11 ilmiah, 104, 105, 106, 108, 109, 110, $113,114,130,132$

imajinatif, 43

Indonesia, 128, 129, 130, 131, 132, 133

informasi, 44, 45, 46

inovatif, ii, $12,51,52,53,54,55,56$,

$57,58,59,78,114$

Inovatif, $v, 11,49,51,53,54,59,60$,

$118,120,121,133$

inspirasi, 79

Instrumen, viii, ix

intelektual, 42, 56, 71

interaktif, ii, 27, 62, 72, 114

internet, 13, 26, 31, 47, 86, 87, 101, 113

\section{J}

jaringan, ii, 13

jurnal, 104, 106, 109, 110, 113, 115

\section{K}

keagamaan, 17, 21

kecerdasan, 17, 21, 63

kepribadian, 17, 21

keterampilan, ii, 11, 16, 17, 27, 28, $30,40,53,54,56,58,65,69$

kompetensi, 11, 13, 27

kompetensi kepribadian, 11

kompetensi pedagogik, 11

kompetensi profesional, 11

kompetensi sosial, 11

komponen, 18, 21

komunitas, 55, 59, 77

kondisi, ii, 13, 15, 19, 22, 32, 41, 46, $67,68,81$

kondisional, 40 
kondusif, 41, 46, 47, 66, 115

konferensi, 100, 114

kongkrit, 44

konstruktif, 16, 113

kreatif, 44

Kreatif, i, v, 11, 23, 40, 42, 44, 46, $48,49,59,60,73,84,117,118$, 119,133

kriteria, 34

kurikulum, 45, 132

L

lingkungan, $17,22,26,40,55,57$, $58,66,77,79,80,81,82,114$, 115,130

literasi, 26, 46

luring, 36, 37, 86, 87, 100, 101

\section{M}

Machmudah, 33, 38, 117

mandiri, 66

Ma'ruf, 64, 73, 118

Maswan \& Muslimin, 16, 22, 118

materi, 12, 18, 22, 26, 28, 29, 30, 31,

$32,33,34,35,36,37,44,45,46$,

$48,56,57,59,64,68,72,76,77$,

$80,82,83,86,87,90,101,104$,

$105,106,111,112,113,115$

Materi, viii, ix

media, 19, 29, 31, 36, 37, 51, 58, 68,

77

Media, i, 21, 22, 31, 38, 48, 60, 73,

$117,118,119,120,130,133$

membaca, 27, 63

menata, 62,82

menganalisis, 11, 27

menggali, 44 mental, 15, 31, 66, 78

Menyenangkan, vi, 11, 76, 80, 82,

$84,116,117,120,121$

Metode, 21, 32, 66

minat, $67,79,81,83$

modal, $11,12,65$

Mohamad, 52, 60, 74, 120

moril, iii

Morris, 43, 48, 118

motivasi, 18, 19, 22, 33, 54, 66, 68, 76,82

mulia, 17, 21

multimodal, 55, 59

Mustafa, i, 41, 42, 44, 48, 52, 54, 59, $60,67,68,70,73,118,128,133$

$\mathbf{N}$

nalar, 44

Nara, 16, 23, 41, 49, 120

nasional, 132

Nasional, 16, 23, 102, 109, 111, 120, 121

negara, 17, 21

novel, 109, 111

Nurjan, 40, 49, 119

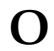

objek, $63,68,81$

one search Indonesia, 13, 104

One Search Indonesia, vii, 109,

111,114

Orlando, 78, 84, 119

Oya, 42, 47, 49, 119

$\mathbf{P}$

PAKIEM, i, ii, 11, 12 
pembelajaran, 44, 45, 46

Pembelajaran, iv, v, vi, vii, 11, 15,

$17,18,20,22,23,25,27,29,33$,

$36,38,40,42,44,46,47,48,49$,

$51,53,54,55,56,57,58,60,62$,

$64,67,69,71,72,73,74,76,80$,

$82,84,86,91,92,93,100,102$,

104, 114, 115, 116, 117, 118, 119,

$120,121,133$

pendekatan, 33, 36, 37, 43, 46, 64,

72

pendemi, 13

pendidik, ii, 11, 12, 13, 17, 18, 21,

$25,29,30,31,32,33,34,35,36$,

$40,41,42,43,47,48,52,54,55$,

$56,57,62,64,65,66,68,69,70$,

$72,77,78,79,80,82,83,86,87$,

$89,90,94,95,97,101,105,106$,

$108,111,113,114$

pendidikan, 128

Pendidikan, 16, 22, 23, 38, 49, 60,

$84,117,118,120,121,128,129$,

$130,131,132,133$

Pengelolaan, viii, ix

pengetahuan, ii, $13,15,16,18,26$,

$28,30,40,41,42,44,45,54,57$,

$58,63,109$

penilaian, 23

peraga, 46

perpustakaan, 26

Perpustakaan, 109, 111

peserta didik, 13, 15, 16, 17, 18, 19,

$20,21,25,26,27,28,29,30,31$,

$32,33,34,35,36,40,41,42,43$,

$47,51,53,54,55,56,57,58,62$,

$63,64,65,66,67,68,69,70,72$,

$76,77,78,79,80,81,82,83,86$,
$87,89,90,100,101,106,108$,

$111,113,114,115$

peta, 44,45

portal garuda, 12, 104, 108, 111

potensial, 11, 13, 55

Prasetya, 30, 37, 116

pribadi, 26, 56, 67, 71

program, 17, 26

psikologis, 15, 77

Putra, 19, 23, 119

\section{$\mathbf{R}$}

realistis, 45, 46, 54, 58, 66

rekreasi, 45

remedial, 67

respon, 95, 97

ruang, $25,36,41,67,84,114,116$

S

Sagala, 81, 84, 119

Sardiman, 18

sekolah, 26

Siregar, 16, 23, 41, 49, 120

sistematis, 18, 44, 45, 71

siswa, 44

skripsi, 104, 110, 113

solusi, 45

spiritual, 17, 21, 57

strategi, 31, 40, 42, 44, 45, 48, 51, $52,56,59,62,68,69,72,76,77$, $80,82,84,115$

Strategi, 129, 133

suasana, 46

sumber, 17, 18, 21, 26, 27, 32, 33,

$36,37,54,57,58,63,106,114$

Suwarsito, 32, 38, 120

Syaifin, 64, 73, 118 
Syaparuddin, 30, 33, 38, 120

\section{$\mathrm{T}$}

Tabel, 44,46

target, 46

teknologi, ii, 34, 54, 55, 58

tenggang rasa, 66

Tes, viii, ix

tesis, 104, 110, 113

tinggi, 128, 132

tingkat, 133

Trinova, 82, 84, 120

tugas, 128

\section{$\mathbf{U}$}

Undang-undang, 16, 23, 120

Undang-Undang, $\mathrm{i}$

Uno, 52, 60, 64, 74, 120

\section{V}

variatif, 40

vasilitator, 27

virtual, 100, 114

Vos, 76, 84, 116

\section{W}

Warsita, 17, 23, 121

website, 13

\section{Y}

youtube, ii, 100

\section{Z}

Zulhafizh, i, 42, 48, 49, 52, 54, 59, $60,68,73,74,102,112,118,121$, $122,131,132$ 